of rear seat occupants in frontal impacts than prevent whiplash in front seat occupants struck from behind. ${ }^{12}$ The compulsory wearing of rear seat belts with rear seat head restraints would lessen the incidence of this and other injuries.

Consultant Trauma and

K M PORTER

Orthopaedic Surgeon,

Birmingham Accident Hospital,

Birmingham B15 1NA

1 Larder DR, Twiss MK, Mackay GM. Neck injury to car occupants using seat belts. In: 29th annual proceedings of the American Association for Automobile Medicine. Des Plaines, Illinois: American proceedings of the American Association for Automobile

2 Deans GT, Magalliard JN, Kerr M, Rutherford WH. Neck sprains-a major cause of disability following car accidents. Injury 1987;18:10-2.

3 States JD. Discussion - neck injury to car occupants using seat belts. In: 29th annual proceedings of the American Assaciation for Automobile Medicine. Des Plaines, Illinois: American Association for Automobile Medicine, 1985:166-8.

Rutherford WH, Greenfield AA, Hayes HRM, Nelson JK. The medical effects of seat belt legislation in the United Kingdom. London: HMSO, 1985.

Mackay GM. Two years experience with the seat belt law in Britain. Arlington, Virginia: Government Industry Liaison Meeting, May 1985. (SAE 851234.)

6 Kahane CJ. An evaluation of head restraints. Federal motor vehicle safety standard 202. Washington, DC: United States Department of Transportation National Highway and Traffic Safety Administration, 1982. (DOT HS 806-108.)

7 Severy DM, Matheson JG, Bechtol CP. Controlled automobile rear end collisions: an investigation of related engineering and medical phenomena. Canadian Services Medical Joumal 1955;11: 729-59.

8 Mackay GM. The nature of collisions. Technical Aspects of Road Safety 1970;43:1-13.

9 Hohl M. Soft tissue injuries of the neck in automobile accidents: factors influencing prognosis. f Bone foint Surg [Am] 1974;56:1675-82.

Norris SH, Watt I. The prognosis of neck injuries resulting from rear end vehicle collisions. f Bone foint Surg [Br] 1983;65:608-11.

11 Juhl $M$, Seerup $\mathrm{KK}$. Cervical spine injuries: epidemiology investigation, medical and social consequences. In: Proceedings of the 6th intemational IRCOBI [Intemational Road Congress on consequences. In: Proceedings of the 6th international IRCOBI [International

12 Mackay GM. The effectiveness of vehicle safety design changes in accident and injury reduction. In: Conference for vehicle safery legislation: its engineering and social implications. London: Institute of Mechanical Engineers, 1973. (Conference publication 16.)

\title{
High density lipoprotein and coronary heart disease
}

\author{
How it protects is still a mystery
}

In 1975 Miller and Miller emphasised the previously described, but largely neglected, inverse relation between plasma high density lipoprotein (HDL) cholesterol concentration and coronary heart disease. ${ }^{1}$ Since then prospective studies in several countries have confirmed this relation and found it independent of other risk factors ( $p$ 998)..$^{2-5}$ Although much is now known of the role of HDL in lipid transport, ${ }^{6-8}$ how it protects against atherogenesis is not understood.

An attractive explanation depends on the participation of HDL in reverse cholesterol transport, whereby cholesterol returns from peripheral tissues to the liver, the major site of cholesterol excretion. ${ }^{9}$ In this process HDL may accept cellular unesterified cholesterol by interacting with specific cell surface receptors, which reversibly bind HDL and regulate cholesterol transport out of the cell. ${ }^{10}$ Low plasma HDL concentrations might therefore mean inefficient reverse cholesterol transport, explaining the inverse relation between plasma HDL concentration and atherosclerosis. Other explanations do not entail HDL in such a direct role; for example, high plasma HDL concentrations may reflect efficient catabolism of triglyceride rich lipoproteins (including remnant particles), which are atherogenic. ${ }^{8}$ The relation of HDL to atherogenesis might be mediated through effects on thrombotic factors such as platelet aggregation, prostacyclin production, and fibrinolysis. ${ }^{11-13}$

As well as providing an additional assessment of the risk of vascular disease, measuring the plasma HDL concentration permits the calculation of plasma low density lipoprotein (LDL) cholesterol concentration, the major atherogenic particle, by the Friedewald formula (plasma LDL cholesterol concentration $(\mathrm{mmol} / \mathrm{l})=$ plasma total cholesterol concentration-plasma HDL cholesterol concentration-plasma triglyceride concentration $/ 2 \cdot 19) .^{14}$

Some studies have emphasised the predictive power of the ratio of the plasma concentration of LDL to HDL in risk assessment. ${ }^{2}$ Knowledge of the plasma HDL concentration may affect clinical management, subjects with a slightly increased plasma total cholesterol concentration due solely to an increased plasma HDL cholesterol concentration do not need treatment. Although the relation of hypertriglyceridaemia to coronary heart disease is not clear, hypertriglyceridaemia in the presence of low plasma HDL cholesterol concentration is possibly associated with an increased risk of vascular disease. ${ }^{15}$ (In subjects with a pronounced family history of vascular disease without an appreciably increased plasma total cholesterol concentration the plasma HDL cholesterol concentration may be low $(<0.9 \mathrm{mmol} / \mathrm{l})$, suggesting familial hypo- $\alpha$-lipoproteinaemia. ${ }^{16}$

The main aim of treating hyperlipoproteinaemia is to reduce the $\mathrm{LDL}$ cholesterol concentration. ${ }^{178}$ Current evidence is insufficient to argue for a causal role for a low plasma HDL cholesterol concentration, although the Helsinki heart study suggested an independent benefit of increasing plasma HDL cholesterol concentration by drug treatment in preventing coronary heart disease. ${ }^{19}$ In addition, a substantial increase in the concentration of serum HDL cholesterol (together with a reduction in that of $\mathrm{LDL}$ cholesterol) followed pharmacological intervention in the cholesterol lowering atherosclerosis study, which resulted in reduced progression of atherosclerotic plaques and their regression in an appreciable number of patients. ${ }^{20}$

What then is a reasonable clinical approach to take? Plasma HDL cholesterol concentration tends to be low in overweight subjects, cigarette smokers, and sedentary subjects ${ }^{21}$ and correcting these factors will tend to increase plasma $\mathrm{HDL}$ concentration. Drugs, particularly thiazide diuretics and nonselective $\beta$ adrenergic blocking agents, may lower plasma HDL cholesterol concentrations, and alternatives should be considered for patients with hyperlipoproteinaemia. ${ }^{22}$ It seems reasonable to adopt a more aggressive approach to lowering plasma LDL cholesterol concentration in the presence of a low plasma HDL cholesterol concentration and to attach more importance to moderate degrees of hypertriglyceridaemia when this is associated with a low plasma HDL cholesterol concentration. Much, however, remains unknown; for example, will increasing the plasma concentration of HDL cholesterol alone protect against coronary heart disease? Some hypolipidaemic drugs, particularly the fibrates and nicotinic acid, increase plasma HDL cholesterol concentration, but so too does alcohol. Given the complicated metabolism of HDL, it seems unlikely that all interventions that increase the concentration of plasma HDL cholesterol will affect the piocess or processes by which it protects against atherosclerosis.

Until we know more, measuring the concentration of plasma HDL cholesterol as part of the fasting lipid profile provides a more comprehensive assessment of the risk of vascular disease and a sounder basis for making therapeutic 
decisions than does measuring plasma total cholesterol alone. The methods for HDL determination need to be standardised, and the unacceptably high coefficient of variation of the methods reduced. Additional measurements of plasma HDL cholesterol concentration will have budgetary implications for departments of clinical chemistry. In future, measuring $\mathrm{HDL}$ subfractions or apoprotein Al may give better estimates of risk than total HDL cholesterol alone.

Reader in Medicine,

D JOHN BETTERIDGE

Department of Medicine,

University College and Middlesex School

of Medicine,

London WC1E 6JJ

1 Miller GJ, Miller NE. Plasma high density lipoprotein concentration and development of ischaemic heart disease. Lancet 1975; i: 16-9.

2 Kannel WB. High density lipoproteins: epidemiologic profile and risks of coronary artery disease. Am $\mathcal{F}$ Cardiol 1983;52:9-12B

3 Castelli WP, Garrison RJ, Wilson PWF, et al. Incidence of coronary heart disease and lipoprotein cholesterol levels. Thë ramingham Study. JAMA 1986;256:2835-8.

4 Miller NE, Forde OH, Thelle DS, et al. The Tromso heart study. High density lipoprotein and coronary heart disease. A prospective case-control study. Lancet 1977; ii:965-8.

5 Gordon DJ, Probstfield JL, Garrison RJ, et al. High density lipoprotein cholesterol and cardiovascular disease: four prospective American studies. Circulation (in press).

Reichl D, Miller NE. The anatomy and physiology of reverse cholesterol transport. Clin Sci $1986 ; 70: 221-31$
7 Patsch JR, Gotto AM Jr. Metabolism of high density lipoproteins. In: Gotto AM Jr, ed. Plasma lipoproteins. New comprehensive biochemistry. Amsterdam: Elsevier, 1987:221-59.

8 Miller NE. High density lipoprotein: a major risk factor for coronary atherosclerosis. In: Shepherd J, ed. Lipoprotein metabolism. London: Baillière Tindall, 1987:603-22. (Clinical endocrinology and metabolism; vol 1.)

9 Glomset JA. The plasma lecithin: cholesterol acyltransferase reaction. $f$ Lipid Res 1968;9:155-67.

10 Bierman EL, Oram JF. The interaction of high density lipoproteins with extrahepatic cells. Am Heart $\mathcal{O}$ 1987;113:549-50.

11 Desai K, Hutton RA, Bruckdorfer KR, Owens JS. Aggregation of isolated platelets is inhibited by the plasma high density lipoprotein sub-class HDL-1. Biochem Soc Trans 1986;14:723-4.

12 Van Sickle WA, Wilcox HE, Malik KV, Nasiletti A. High density lipoprotein induced cardiac prostacyclin synthesis in vitro: relationship to cardiac arachidonate mobilisation. $\mathcal{J}$ Lipid Res 1986;27:517-22.

13 Saku K, Ahmad M, Glas-Greenwalt P, et al. Activation of fibrinolysis by apolipoproteins of high density lipoproteins in man. Thromb Res 1985;39:1-8.

14 Friedewald WT, Levy RI, Frederickson DS. Estimation of the concentration of low density lipoprotein cholesterol in plasma without use of the preparative ultracentrifuge. Clin Chem 1972;18:499-502.

15 Castelli WP. The triglyceride issue: a view from Framingham. Am Heart $f$ 1986:112:432-7.

16 Ordovas JM, Schaefer ER, Salem D, et al. A polipoprotein A-I gene polymorphism associated with premature coronary artery disease and familial hypoalphalipoproteinaemia. $N$ Engl f Med 1986;324:671-7.

17 Consensus Development Panel. Lowering blood cholesterol to prevent heart disease. JAMA

18 Study Group of the European Atherosclerosis Society. Strategies for the prevention of coronary heart disease, a policy statement of the European Atherosclerosis Society. Eur Heart $\mathcal{F}$ 1987;8: 77.88 .

19 Manninen V, Elo MO, Frick MH, et al. Lipid alterations and decline in the incidence of coronary heart disease in the Helsinki Heart Study. $\mathcal{F} A M A$ 1988;260:641-51.

20 Blankenhorn DH, Nessum SA, Johnson RL. Beneficial effects of combined colestipol-niacin therapy on coronary atherosclerosis and coronary venous bypass grafts. JAMA 1987;257: 3233-40

21 Betteridge DJ. High density lipoproteins and atherosclerosis. Biochem Soc Trans 1978;6:888-93.

22 Weidman P, Vehlinger DE, Gerger A. Antihypertensive treatment and serum lipoproteins. f Hyperten 1985;3:297-306.

\title{
Introducing aptitude testing into medicine
}

\author{
Surgeons lead the way
}

In many countries employers use techniques of objective assessment to select staff for key positions. In Britain these techniques are widely used in industry, commerce, the civil service, and the armed forces, but they have not been used by doctors. Now the Royal College of Surgeons of England has drawn attention to the potential of personality assessment techniques and aptitude testing as aids for selecting surgical trainees. ${ }^{1} \mathrm{~A}$ working party has been set up by the college to establish these techniques not only for selection but also for assessment during training.

The techniques include using questionnaires to explore interests, motivation, and aspects of personality; ability testing of intelligence, aptitude, and attainment; and behavioural exercises that simulate problems typically encountered in the job under consideration. All these data are collected on a computer, scored, and then combined with the result of an interview with structured rather than random questions. The aim is to ensure that the applicant and the job are well matched. This is particularly relevant to specialties such as surgery, in which applications for entry outnumber training posts. The present subjective and haphazard forms of selection are no longer adequate.

The questionnaire and the tests used in selection must be relevant to the specialty, and so a criterion or task analysis must first be performed. Greenberg et al asked 115 surgeons and surgical residents which of 35 personality traits they considered to be the most appropriate for a surgeon; agreement was greatest for decisiveness, fairness, good team participation, flexibility, admitting to errors, discipline, considering all the facts, motivation, and an ability to listen. ${ }^{2}$ Schueneman et al tested surgical residents and found that the two factors most predictive of operative skill were visuospatial organisation and stress tolerance. ${ }^{3}$ After observing surgeons at work in operating theatres, wards, and outpatient departments and interviewing surgeons and surgical trainees in The
Netherlands Van De Loo established criteria for selecting surgical trainees based on (a) intelligence (verbal, spatial, and numerical); (b) operative skill (dexterity, psychomotor ability, attention, and concentration); (c) stability and organisation (emotional stability, common sense, and organising and planning ability); (d) work attitude (motivation, accuracy and carefulness, energy, drive, and stamina); and (e) cooperation (sociability, independence, self criticism, and empathy). ${ }^{4}$

The techniques of assessment must be based on a sound rationale and be demonstrably valid; they must be economically feasible, taking account of the time taken to perform and mark the tests; and they must be politically acceptable to both those using the tests and those being tested.

The answers to the questionnaires and the test results may be weighted according to the criterion analysis for the specialty. For example, the test for visuospatial organisation might carry a higher score for a prospective urologist, who will have to perform much endoscopic surgery, than for a general or orthopaedic surgeon, who may expect to manage major trauma. The results of tests already performed on surgical trainees in The Netherlands suggest that there is not one profile of a surgeon but rather a series; this finding should reassure those who fear surgical "clones" emerging if such selection methods are adopted.

The armed services with their system of yearly review have had an unrivalled opportunity to validate their initial selection techniques. Since the early 1940s the Royal Air Force has developed and expanded its aptitude testing. Task analysis, and hence the definition of tests, exists not only for pilots but also for navigators, air engineers, air loadmasters, air electronics operators, air traffic controllers, and fighter controllers. ${ }^{5}$ The results have confirmed that factors other than aptitude are important for success in training, although aptitude is the most discriminatory factor. Weighting the 